九州大学学術情報リポジトリ

Kyushu University Institutional Repository

\title{
Soft Actuator with Large Volumetric Change using Vapor-liquid Phase Transition
}

Noguchi, Tomoki

Department of Mechanical and Aerospace Engineering, Kyushu University

Tsumori, Fujio

Department of Mechanical Engineering, Kyushu University

http://hdl. handle. net/2324/4403546

出版情報: Japanese Journal of Applied Physics. 59 (SI), pp. SIIL08-，2020-06-01. 応用物理学会 バージョン：

権利関係 : 


\title{
Soft Actuator with Large Volumetric Change using Vapor-liquid Phase Transition
}

\author{
Tomoki Noguchi ${ }^{1}$ and Fujio Tsumori ${ }^{2}$ \\ ${ }^{1}$ Dept. of Mechanical and Aerospace Engineering, Kyushu University, Fukuoka 819-0395, \\ Japan \\ ${ }^{2}$ Dept. of Mechanical Engineering, Kyushu University, Fukuoka 819-0395, Japan \\ E-mail: tsumori@mech.kyushu-u.ac.jp
}

\begin{abstract}
Soft robotics has become an attractive research topic with the recent development of soft actuators. Herein, we propose a deformable soft actuator with large volumetric changes. The proposed elastomer contains liquid droplets; their transition from the liquid phase to the vapor phase can be controlled by heat. We chose silicone and urethane rubbers as the matrix materials; droplets of water and fluorine were dispersed homogeneously in the rubber matrix as micelles or solutes. After curing the rubber, bubbles appeared owing to microwave heating. We succeeded in generating a fine bubble structure using the proposed method, and we could reduce the leakage of the droplet material using urethane as the matrix material. Finally, we attempted to fabricate a small actuator to work in the channels. The proposed method can be useful for miniaturized soft robots.
\end{abstract}

\section{Introduction}

In this work, we propose a soft actuator that can deform due to a large volumetric change caused by the vapor-liquid phase transition. Recently, various soft actuators have been proposed and developed for soft robotics, a growing field in which robots composed of soft and flexible materials [1] are used in industrial applications. Some researchers have developed new robot models based on the soft organs of living creatures [2], such as octopus [3, 4], jellyfish [5], worms [6, 7], cilia [8-12]. One of the most important components of soft robotics is the soft actuator or artificial muscle, therefore, several models that use photosensitive dielectric polymers [13-15], or ionic liquid-based gels [16] have been developed. Another approach is to use physical-based actuators, such as the pneumatic type actuators (the most popular one) [13, 14], which are controlled by air pressure through an air tube, or magnetic actuators, which are composed of magnetic powder and a flexible matrix, such as an elastomer or a gel [6-12, 19-25]. Furthermore, these physical actuators provide excellent responsiveness using external power sources.

Another type of physical-based actuators, which were the main focus of this work, employs a predefined material, such as ethanol, dispersed inside liquid bubbles, resulting in a large volumetric change of the elastomer, made of silicone for example, after a gas-liquid phase transition [26], as shown in Fig. 1. As a compressor or an air tube is not required, the actuator could work in various 
locations without tethering. In this work, we propose a method to generate finer bubble structures in the material than those in the conventional method by employing an aqueous solution of polyethermodified silicone oil, as it decreases the interfacial energy between rubber matrix and liquid bubbles. A fluorine-based liquid, which has a low-boiling-point, was also prepared as an alternative, therefore, a low driving temperature was used for both cases. Furthermore, we used an urethane rubber, which has lower gas permeability than silicone rubber, as an alternative elastomer to evaluate the leakage reduction of the material from the droplet.

Our new material consists of fine bubbles, enabling a robot to work with small channels present in lab-on-a-chip applications. Furthermore, we have demonstrated some examples of the proposed actuator with small channels, whose temperature was controlled by heating wires. The proposed material could also be used for many other actuation systems that use shape-memory alloys $[27,28]$.

\section{Materials}

In this work, ethanol and pure water were used as additive materials to make liquid bubbles in a rubber matrix. We added a $2 \%$ mass solution of polyether-modified silicone oil (KF354L, Shin-Etsu Chemical), as a surfactant, to pure water, decreasing, therefore, the surface energy of the liquid bubbles. A fluorine-based liquid (Novec7000, 3M), which has a low boiling point $\left(34{ }^{\circ} \mathrm{C}\right)$, therefore, realizing the gas-liquid phase transition at lower temperatures, was also prepared.

First, these liquid materials were mixed with the silicone rubber (Ecoflex00-10, SmoothOn) by placing them in a sample tube with silicone rubber, resulting in a solution with $12 \%$ of mass concentration of liquid material. The tube was inserted in a stirring deaerator (SK-350T, Shashin Kagaku) for $90 \mathrm{~s}$ of mixing, resulting in a homogeneous mixture at this moment. However, the size of the droplets of ethanol increased due to the coalescing process and they became coarser. After 10 min, these coarse droplets floated to the surface, and the silicone and ethanol phases were separated into two layers. Figure 2 shows the samples obtained 30 min after the mixing procedure was completed. For the ethanol and silicone rubber sample, the separation resulted in two distingue layers, as shown in Fig. 2(a), however, the other ones were still homogeneous. The sample with water, Fig. 2(b), was white and opaque as the mixture probably changed to an emulsion state, in which the droplets became tiny micelles. In contrast, the color of the sample with fluorine, Fig. 2(c), was transparent, indicating that the molecules of the liquid material might have dispersed into the matrix.

The homogeneous state of the mixtures in Fig. 2(b) and Fig. 2(c) was obtained after curing the silicone rubber. As a result, these materials would be helpful in long procedures, or procedures with high reproducibility, as the bubble structure would not change during the curing period. These liquid materials were, therefore, selected for the following experiments. 
In addition, preliminary experiments indicated that leakage of the liquid material through diffusion in the silicone matrix occurred as silicone has a much higher gas permeability. To mitigate this problem, another matrix that was composed of urethane rubber (VytaFlex30, Smooth-On) was fabricated in addition to the same silicone rubber. The gas permeability of urethane, which depends on the type of gas, is one-tenth to one-hundredth of that of the silicone rubber.

The process flow for preparing the material is shown in Fig. 3. Silicone or urethane rubber was premixed with water or fluorine liquid by manually shaking the recipient where they were placed. At this stage, the mixture was not homogeneous, and many air bubbles were noticed. Afterward, the sample was mixed using a stirring deaerator for $3.0 \times 10^{2} \mathrm{~s}(5 \mathrm{~min})$ at a rotation speed of $30 \mathrm{rpm}$ and a revolution speed of $1340 \mathrm{rpm}$, as indicated in Fig. 3(a). The mixture ratio of the droplet material to the total solution was $10 \%$. After mixing, the rubber solution was poured into a plastic container and kept at room temperature for approximately $5.4 \times 10^{4} \mathrm{~s}(15 \mathrm{~h})$ to be cured, Fig. 3(b), and, thereafter, cut into any required shape, Fig. 3(c).

The cured mixtures were homogeneous; however, they could not work as an actuator indicated by Fig. 1, for example, the volumetric change of a mixture composed by fluorine, due to the vapor transition in boiling water, is not enough to generate bubbles despite its low boiling point $\left(34^{\circ} \mathrm{C}\right)$. To solve this problem, the energy from the microwaves was used. Figure 4 schematically shows the different microstructures of the samples after each stage: mixing, curing, and microwave heating. After the curing stage, only the structure of the sample with ethanol changed, as its droplets grew and its structure became coarser due to coalescence. As a result, this mixture could show large volumetric changes and liquid-gas phase transition after heating, as its droplets were coarse and their curvature was larger (higher internal pressure).

Meanwhile, regarding the mixtures composed of water or fluorine, the generation of bubbles was possible after microwave heating. These bubbles were still present after cooling, Fig. 3(e), indicating that high-energy heating, such as microwave emission, was unnecessary after their formation. However, some of the liquid material leaked during the microwave heating stage, therefore, we placed the whole system in a recipient containing the liquid material, Fig. 3(f). As a result, the quantity lost due to the leakage could be refilled, resulting in a material with higher responsiveness.

\section{Diffusion and Bubble Generation}

The water or fluorine liquid of the proposed system should be trapped inside its matrix; however, these components could be diffused through it, leading to leakage of the liquid material. To solve this problem, first, we conducted an experiment comparing the diffusivities of silicone and urethane elastomers. We prepared 4 kinds of materials; silicone materials mixed with water and fluorine liquid, and urethane rubbers mixed with the same liquids. After curing, each sample was, respectively, cut into cubes of several millimeters, kept at air atmosphere and room temperature, and 
heated with microwaves every $3600 \mathrm{~s}(1 \mathrm{~h})$ to generate bubbles.

An optical photo of the state of each material based on the hours kept at room temperature is shown in Fig. 5. The area with the highest concentration of bubbles, named, in this work, as bubble area, was located in the center of each sample. Bubbles were present in all silicone samples that were mixed with water and were generated in these samples even after $5 \mathrm{~h}$ of exposure. In the case of silicone samples with fluorine, the area near the sample surface, where no bubbles were present, was thicker and increased with exposure time. Finally, there were no bubbles in the samples after $3 \mathrm{~h}$ of exposure time. Considering the silicone matrix, the permeability of fluorine was higher than that of water, indicating that fluorine diffused from the sample surface. Meanwhile, the samples consisting of the urethane matrix, generally, showed a lower permeability than that of the respective silicone sample. In this experiment, all urethane samples generated bubbles even after $5 \mathrm{~h}$ of storage.

Furthermore, the shape of the silicone samples was preserved while the urethane samples deformed, as the temperature required to soften the urethane structure was lower than that of silicone. The heating was stopped at the moment that bubbles were generated in the samples. As a result, the samples with fluorine, whose boiling temperature is relatively low, required a lower heat than those with water, resulting in less deformation of the samples with fluorine. Meanwhile, the high deformation of the urethane samples with fluorine prevented them to be applicable for this heating step.

In this section, we presented some samples prepared by our newly proposed method. As a result, fine bubbles were generated as the additive liquid was dissolved in the elastomer. In addition, we showed that a matrix made of urethane could avoid the diffusion of additive materials. These characteristics are useful for the material when applied in miniaturized actuators.

\section{Repeated Actuation}

Afterward, we repeated the heating and cooling procedure in water, as shown in Fig. 6. We prepared two water baths, at $25{ }^{\circ} \mathrm{C}$ and $60{ }^{\circ} \mathrm{C}$, respectively, and alternately dipped the samples composed of silicone or urethane and fluorine in the baths. The change in volume of each sample almost finished after approximately $10 \mathrm{~s}$, therefore, the dip period, which is the time that the samples were dipped, was set to $15 \mathrm{~s}$.

Figure 7 indicates the volume expansion of samples in the hot bath $\left(60{ }^{\circ} \mathrm{C}\right)$ in their volume contraction in the cold bath $\left(25^{\circ} \mathrm{C}\right)$. We, thereafter, measured the linear expansion rate at each bath from the image. Figure 8 shows the linear expansion ratio of the samples at each step. The data were normalized by the rate at the first step. At the first heating, the expanded ratios of both silicone and urethane were approximately 1.4; however, it decreased with further steps. Furthermore, some of the fluorine inside the sample leaked from its surface as gas bubbles. The decrease in the volume expansion ratio of the silicone sample was larger, as the permeability of the fluorine material in the 
silicone was higher. The gas permeability in silicone was, generally, 10 to 100 times higher than that in urethane [29].

\section{Actuation in Channels}

We tried to actuate a small beam or strip of a droplet-dispersed elastomer. Figure 9 shows a schematic diagram of the experimental setup. Four nichrome wires were placed at the bottom of a channel made of PDMS (Sylgard 184, The Dow Chemical), and a strip sample of the urethane-based material with the fluorine liquid was placed in the channel. This setup was prepared based on the crawling motion of earthworms, in which the volumetric change would gradually propagate from the right end to the left one of the strip sample. We prepared two actuation setups; in the first one the sample was exposed to air and in the other one, it was exposed to water. The width and height were $5.0 \mathrm{~mm}$ and 5.0 in the first setup, and $5.0 \mathrm{~mm}$ and $3.0 \mathrm{~mm}$ in the second setup, respectively.

Figure 10 shows the snapshots of the first setup. In this setup, every $30 \mathrm{~s}$, the rightmost unheated nichrome wire was heated (heating step), resulting in the increase of volume from the right region of the sample to the left side, as each heating step proceeded. After the first and second steps, it was noticeable that the heat was transmitted to the left part of the sample, therefore, the increase in volume was not observed in further heating steps.

Figure 11 shows the snapshots of the second setup. In this experiment, the nichrome wire at the leftmost part of the sample repeatedly switched from heated and unheated states. As the water was responsible to dissipate heat from the sample, the volume of the affected region changed according to the wire state. Furthermore, the sample in this experiment was thinner than that used in the previous one, to reduce the response time. The water environment is also expected to prevent the leakage of fluorine. This proposed experiment could resemble the mentioned crawling motion and, therefore, has the potential for real case applications. For this purpose, the friction of the surface will be properly evaluated in our future work.

\section{Conclusion}

In this work, we proposed an elastomer material dispersed with liquid bubbles. We successfully fabricated fine bubble structures using a new method that can avoid a coarse structure of the mixed material. We, thereafter, generated water micelles using a surfactant and dissolved a fluorine-based liquid into identical silicone rubber samples. In both cases, the mixed material was homogeneous and exhibit a fine structure. These materials were subsequently heated by microwave irradiation, and fine bubbles were also generated, enabling them to be used in an actuator. Furthermore, we fabricated bubble structures in urethane rubbers and proved that these systems could decrease the leakage of fluorine inside the bubbles due to the low permeability of urethane.

Fine bubbles and low leakage are necessary features to miniaturize the proposed soft actuator, 
as coarse bubbles are not suitable for small structures and the leakage rate would be higher. We demonstrated small strips actuated in channels and showed the potential of the proposed material for soft microrobots. Some problems related to heat propagation; however, have not been solved yet, as the improvement of the cooling system is required.

Moreover, we would like to employ this material for a 3D printing system. As the printed structure could be actuated, the system may be called 4D printing [6, 9, 30-33]. We are now preparing two or more types of materials with different expansion ratios that will be arranged in a 3D structure and their motion will be designed based on the heating procedure.

\section{Reference}

[1] D. Trivedi, C. D. Rahn, W. M. Kierb, and I. D. Walkerc, Appl. Bionics. Biomech., 5, 99 (2008).

[2] S. Kim, C. Laschi, and B. Trimmer, Trends Biotechnol., 31, 287 (2013).

[3] C. Laschi, M. Cianchetti, B. Mazzolai, L. Margheri, M. Follador, and P. Dario, Adv. Robot., 26, 709 (2012).

[4] M. Wehner, R. L. Truby, D. J. Fitzgerald, B. Mosadegh, G. M. Whitesides, J. A. Lewis, and R. J. Wood, Nature, 536, 451 (2016).

[5] J. C. Nawroth, H. Lee, A. W. Feinberg, C. M. Ripplinger, M. L. McCain, A. Grosberg, J. O. Dabiri, and K. K. Parker, Nat. Biotechnol., 30, 792 (2012).

[6] H. Shinoda, S. Azukizawa, K. Maeda, and F. Tsumori, J. Electrochem. Soc., 166, 3235 (2019).

[7] M. Furusawa, K. Maeda, S. Azukizawa, H. Shinoda, and F. Tsumori, J. Photopolymer Sci. Technol., 32, 309 (2019).

[8] H. Shinoda, S. Azukizawa, and F. Tsumori, Proc. microTAS2018, 2018, p. 679.

[9] S. Azukizawa, H. Shinoda, K. Tokumaru, and F. Tsumori, J. Photopolym. Sci. Technol., 31, 139 (2018).

[10] R. Marume, F. Tsumori, K. Kudo, T. Osada, and K. Shinagawa, Jpn. J. Appl. Phys., 56, 06GN15 (2017).

[11] F. Tsumori, R. Marume, A. Saijou, K. Kudo, T. Osada, and H. Miura, Jpn. J. Appl. Phys., 55, 06GP19 (2016).

[12] F. Tsumori, A. Saijou, T. Osada, and H. Miura, Jpn. J. Appl. Phys., 54, 06FP12 (2015).

[13] J. Lv, W. Wang, W. Wu, and Y. Yu, J. Mater. Chem. C Mater., 3, 6621 (2015).

[14] Y. Cheng, K. Ren, D. Yang, and J. Wei, Sens. Actuators. B Chem., 255, 3117 (2018).

[15] S. Shian, K. Bertoldi, and D. R. Clarke, Adv. Mater., 27, 6814 (2015).

[16] T. Fukushima, K. Asaka, A. Kosaka, and T. Aida, Angew. Chem. Int. Ed. Engl., 44, 2410 (2005).

[17] C. Chou and B. Hannaford, IEEE Trans. Rob. Autom., 12, 90 (1996).

[18] R. F. Shepherd, F. Ilievski, W. Choi, S. A. Morin, A. A. Stokes, A. D. Mazzeo, X. Chen, M. 
Wang, and G. M. Whitesides, PNAS, 108, 20400 (2011).

[19] H. Shinoda and F. Tsumori, Jpn. J. Appl. Phys., 57, 06HJ05 (2018).

[20] D. Maede, F. Tsumori, T. Osada, and K. Kudo, IEEJ Trans. Electric. Electronic Eng., 138, 48 (2018) [in Japanese].

[21] F. Tsumori, K. Hatama, H. Kang, T. Osada, and H. Miura, Proc. IEEE NEMS, 2013, p. 845.

[22] K. Hatama, F. Tsumori, Y. Xu, H. Kang, T. Osada, and H. Miura, Jpn. J. Appl. Phys., 51, 06FL14 (2012).

[23] F. Tsumori and J. Brunne, Proc. IEEE MEMS, 2011, p. 1245.

[24] F. Tsumori, N. Miyano, and H. Kotera, J. Jpn. Soc. Powder Powder Metallurgy, 56, 133 (2009) [in Japanese].

[25] F. Tsumori, N. Miyano, and H. Kotera, J. Jpn. Soc. Powder Powder Metallurgy, 56, 127, (2009) [in Japanese].

[26] A. Miriyev, K. Stack, and H. Lipson, Nat Commun, 8, 596 (2017).

[27] J. V. Humbeeck, Mater. Sci. Eng. A, 273-275, 134 (1999).

[28] L. Petrini and F. Migliavacca, J. Metallurgy, 501483 (2011).

[29] T. Harusue, H. Ontsuka, and Y. Ohtake, and Nihonn G. Kyoukaishi, 83, 14 (2010) [in Japanese].

[30] A. S. Gladman, E. A. Matsumoto, R. G. Nuzzo, L. Mahadevan, and J. A. Lewis, Nat. Mater., 15, 413 (2016).

[31] S. Azukizawa, H. Shinoda, and F. Tsumori, Proc. IEEE MEMS, 2019, p. 248.

[32] S. Azukizawa, F. Tsumori, H. Shinoda, K. Tokumaru, K. Kudo, and S. Kazunari, Proc. MicroTAS, 2017, p. 623.

[33] F. Tsumori, H. Kawanishi, K. Kudo, T. Osada, and H. Miura, Jpn. J. Appl. Phys., 55, 06GP18 (2016). 


\section{Figure Captions}

Fig. 1 (Color online) Schematic image of the proposed material.

Fig. 2 Mixtures of silicone and three kinds of liquid materials after $30 \mathrm{~min}$; (a) mixture with ethanol, (b) water with the surfactant, and (c) fluorine-based liquid. Ethanol and silicone were separated, whereas homogeneous states were obtained in the other samples.

Fig. 3 (Color online) Process flow for preparing the proposed material.

Fig. 4 (Color online) Schematic illustrations of three types of mixtures. The initial states are different in these three cases. After curing, the ethanol droplets grow due to coalescence. Water micelles and molecules of fluorine remained even after the curing of the silicone matrix. These cured homogeneous materials generate gas bubbles by microwave heating. During heating, liquid materials diffused to nucleation sites, generating larger bubbles.

Fig. 5 (Color online) Image of samples after heating. Silicon and urethane rubbers with water and fluorine liquid bubbles after 1,2,3,4, and $5 \mathrm{~h}$ of air exposure.

Fig. 6. (Color online) Schematic experiment image of repeated heating and cooling in water baths.

Fig. 7. (Color online) Images of the samples in water baths. (a) Silicone with fluorine and (b) urethane with fluorine.

Fig. 8. (Color online) Linear expansion ratio of the samples at each step.

Fig. 9. (Color online) Schematic diagram of the experimental setup of actuation in the channel.

Fig. 10. (Color online) Snapshots of actuation in the air channel.

Fig. 11. (Color online) Snapshots of the actuation in the water channel. 


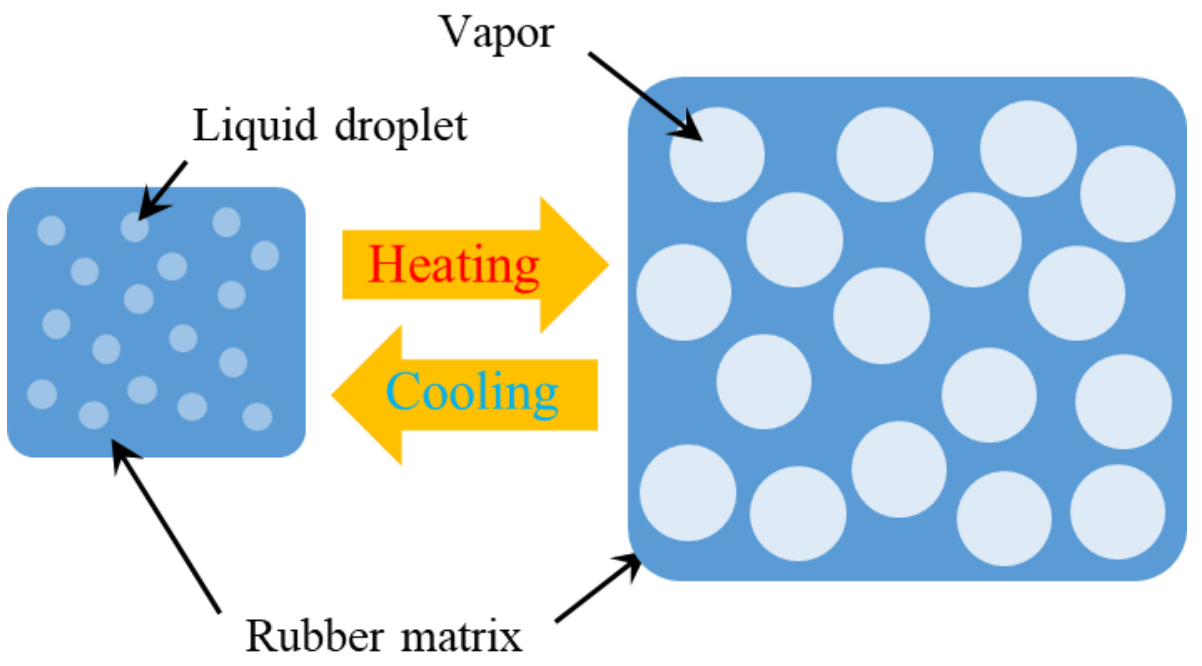

Fig. 1 (Color online) 


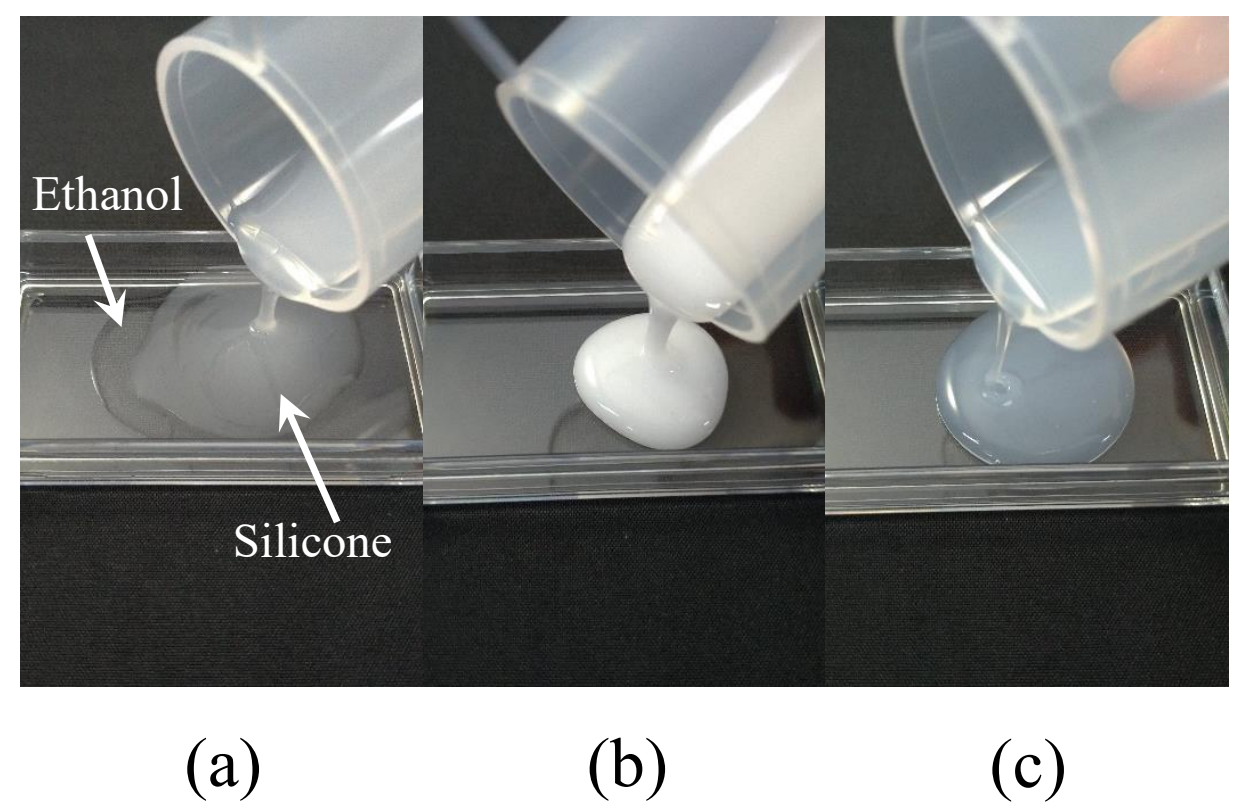

Fig. 2 (Color online) 


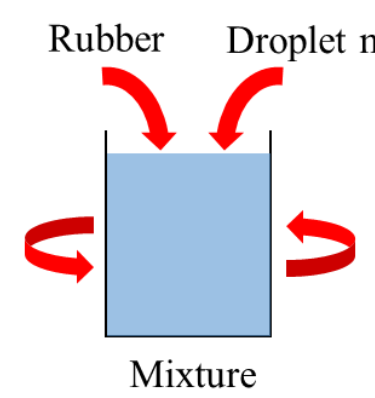

(a)

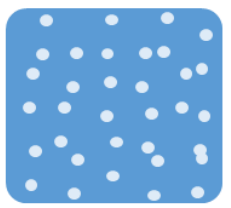

(e)

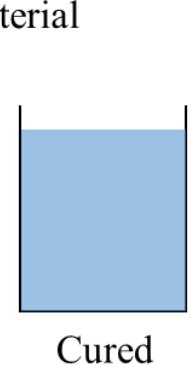

(b)

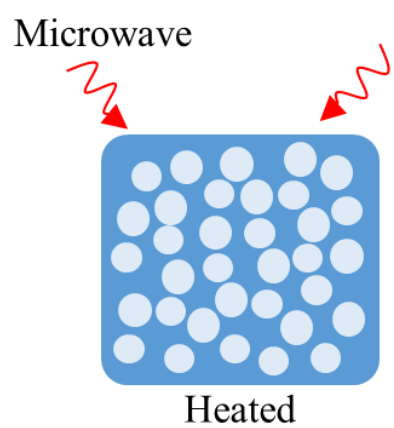

(d)

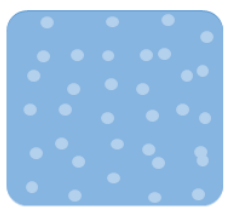

Soak

(f)

Fig. 3 (Color online) 


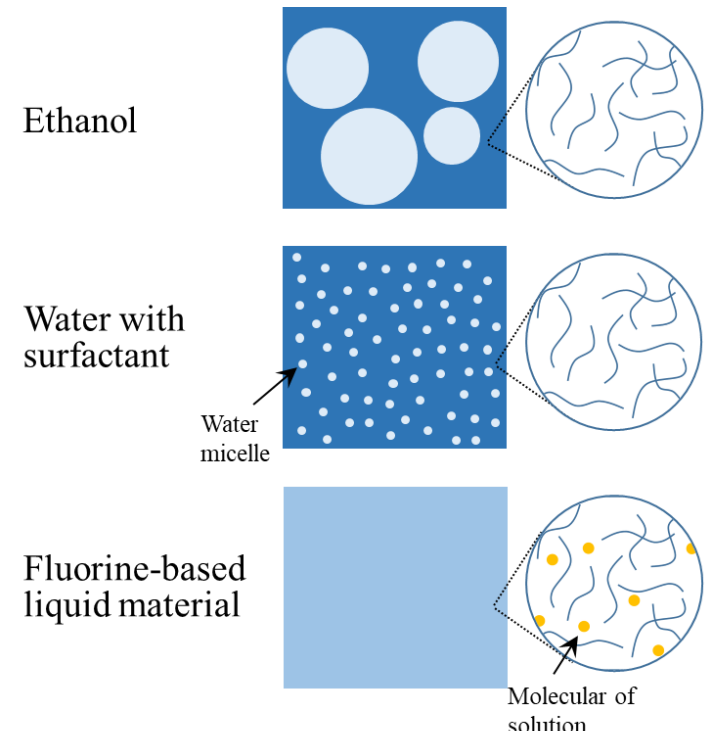

As mixed
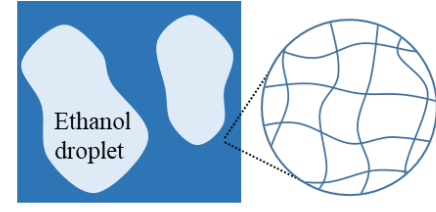

Cured silicone
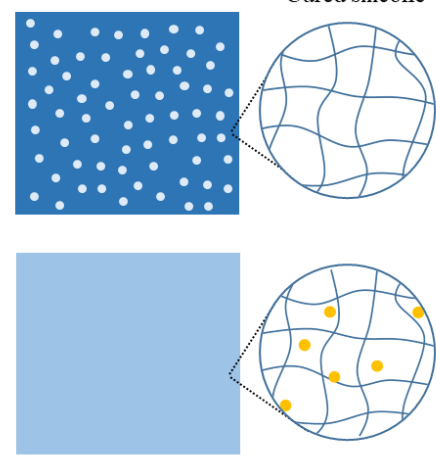

As cured
Diffusion and

migration of

liquid material
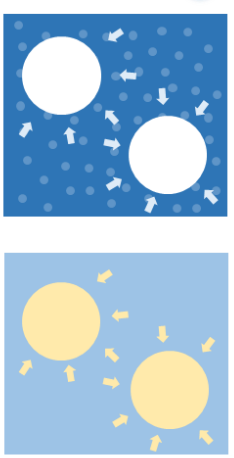

As heated by microwave

Fig. 4 (Color online) 


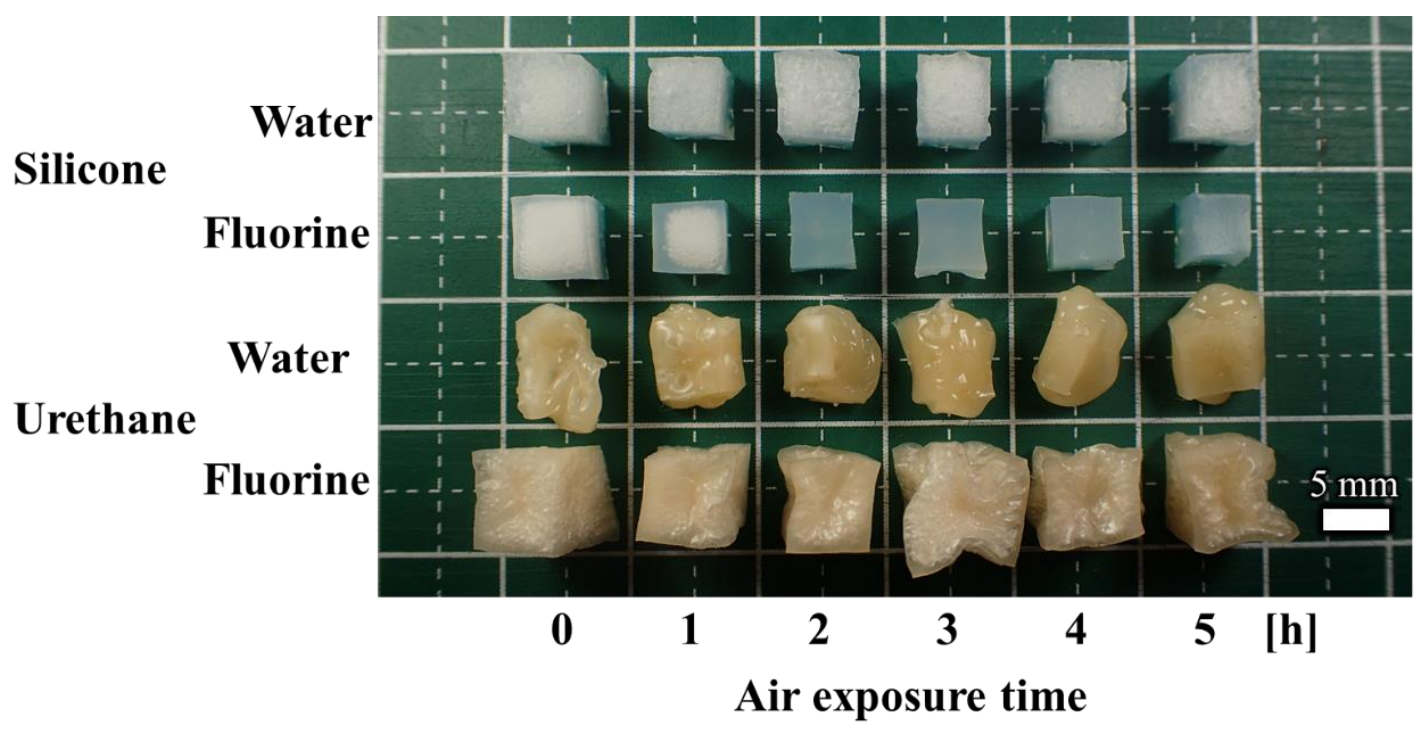

Fig. 5 (Color online) 


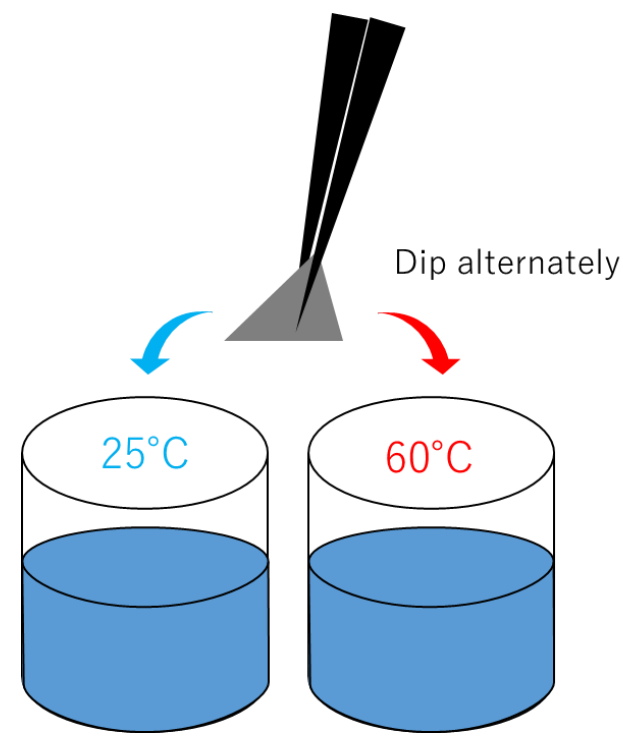

Fig. 6 (Color online) 


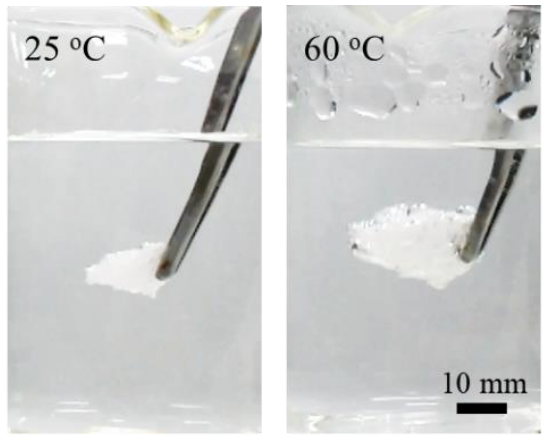

(a)

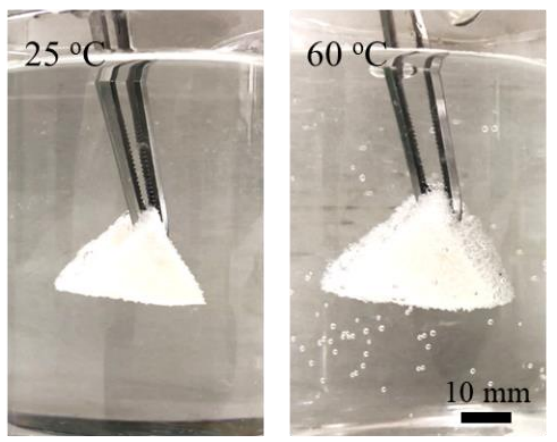

(b)

Fig. 7 (Color online) 

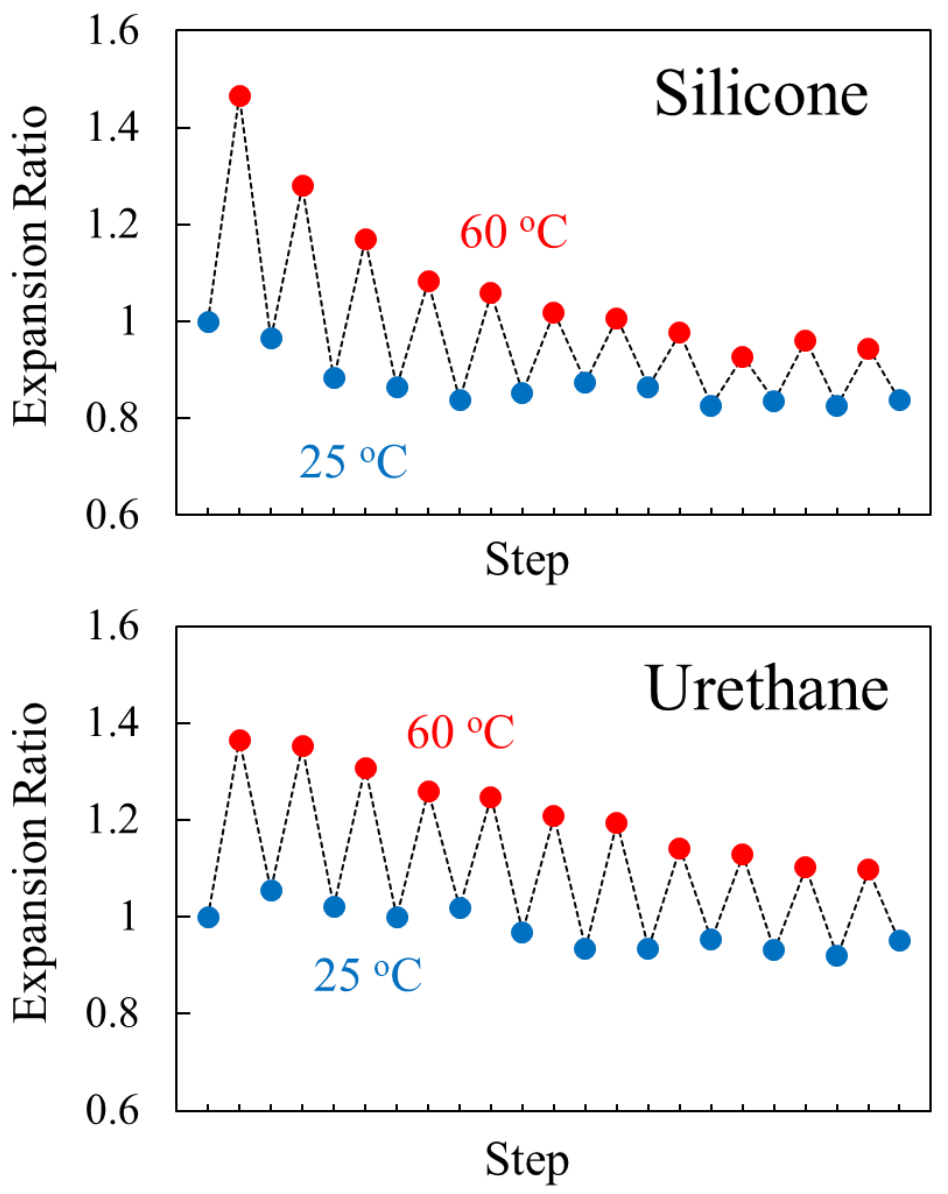

Fig. 8 (Color online) 


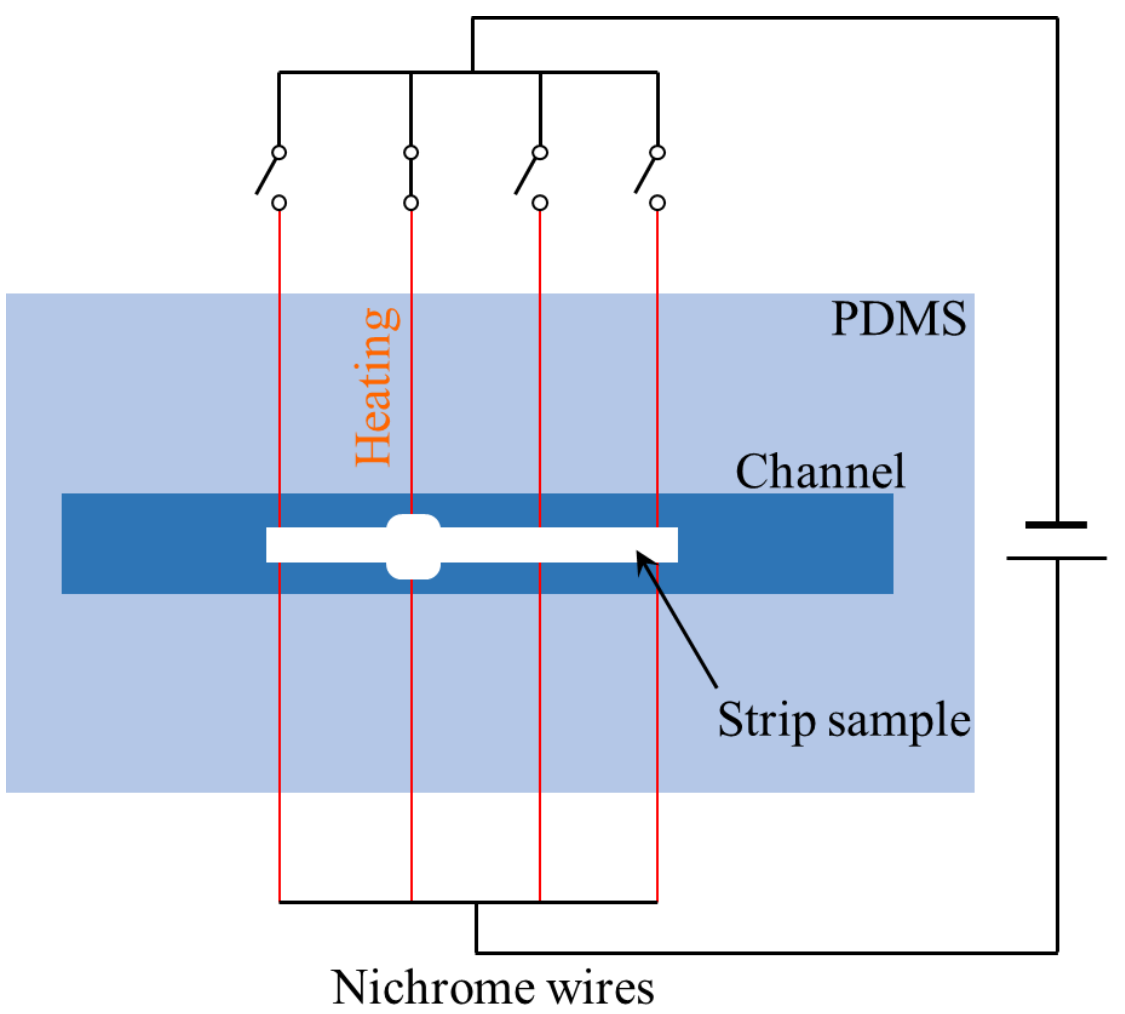

Fig. 9 (Color online) 

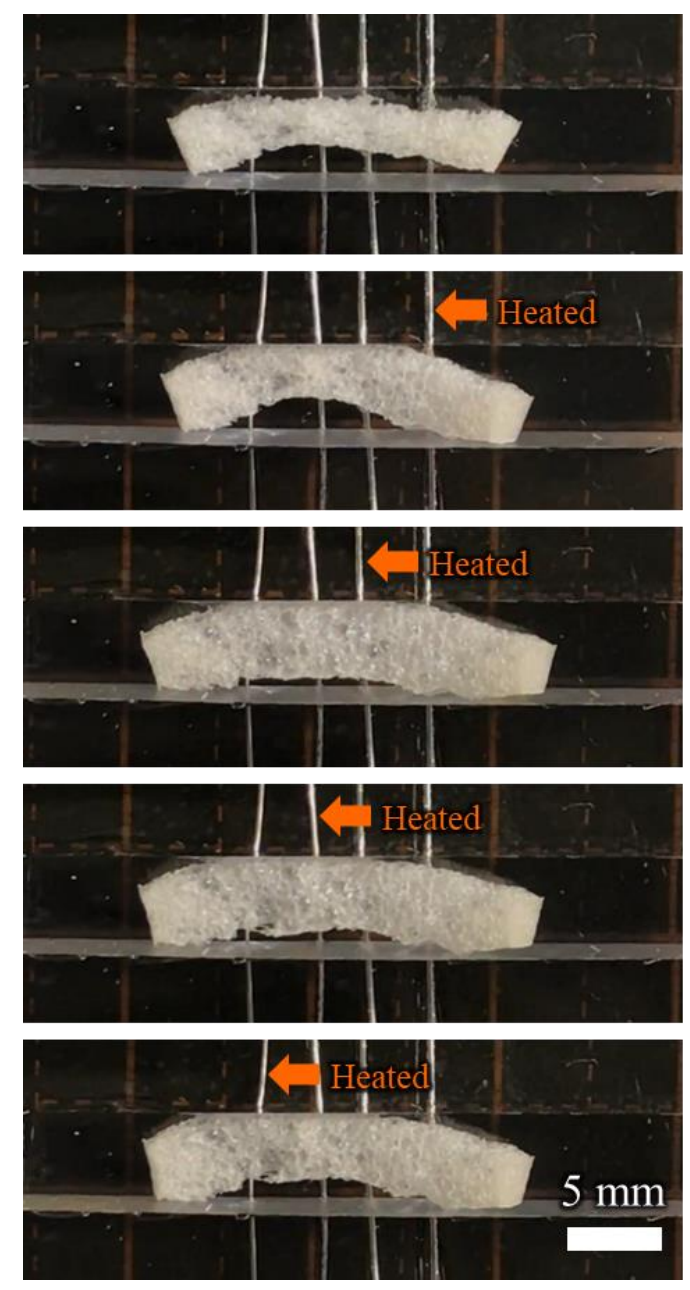

Fig. 10 (Color online) 


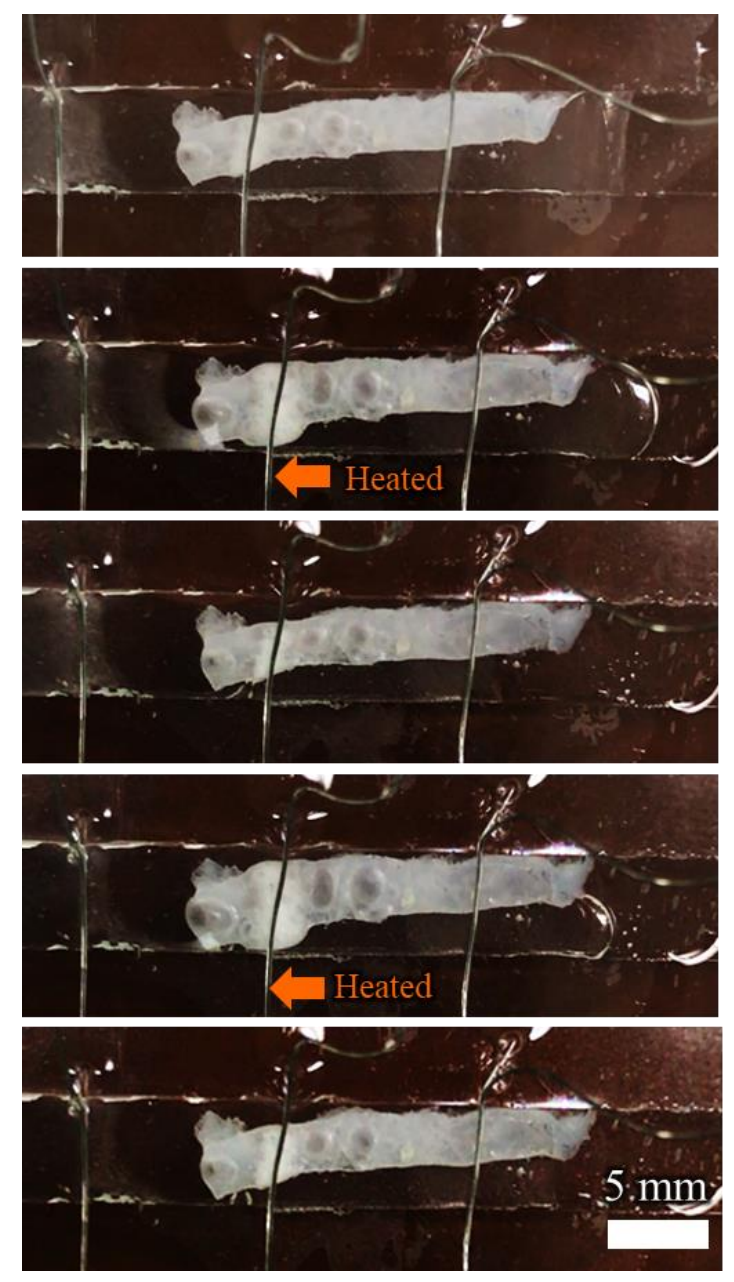

Fig. 11 (Color online) 